\title{
The Case of Civic Society Organization: Citizens' Engagement into Responsible Research and Innovation Actions Through the Social Media
}

\author{
Jelena Mazaj \\ CESIE, Italy \\ Via Roma 94, 90133 Palermo, Italy \\ jelena.mazaj@cesie.org \\ Received 21 October 2016 \\ Revised 4 February 2017 \\ Accepted 9 February 2017 \\ Published 10 April 2017
}

\begin{abstract}
In this paper, we emphasize where socio-economic organizations such as CESIE in Italy, form the platform to advance citizens' activities to reshape the power structure in nations, focusing on social and online media as the basic tool to create such influential activities that impact research and innovation, where particular examples are presented.
\end{abstract}

Keywords: Civil society organization; citizens' engagement; responsible research and innovation; social media.

PACS Number(s): 89.65.Ef, 89.65.Cd, 89.65.Gh

\section{Introduction}

Research and Innovation (R\&I) are flagship initiatives of the EU2020 development strategy, which consists of six elements: Gender Equality, Science Education, Ethics, Open Access, Governance and Engagement and cooperation of all societal actors. It means that researchers, industry, policymakers and civil society work together in joint R\&I to focus on specific global challenges for global sustainability. ${ }^{1}$ However, different obstacles limit such cooperation: understanding of needs, communication, institutional barriers, sharing practices, financial limits, etc.

Nowadays, Civil Society Organizations (CSOs) play a key role in the establishment of successful cooperation practices between different groups of stakeholders aiming to stimulate positive changes in socio-economic and political systems, and for

This is an Open Access article published by World Scientific Publishing Company. It is distributed under the terms of the Creative Commons Attribution 4.0 (CC-BY) License. Further distribution of this work is permitted, provided the original work is properly cited. 
this reason, they use different communication tools. During the last decade, the social and online media shaped the communication attitude of EU society and became the daily tool for exchange of information, creating online societies, which share thoughts, ideas, express their opinions and participate in democratic online processes (community development, e-governance, crisis management, etc. $)^{2,3}$

This article provides information about CSO work with social media to create interactive, low-cost, unlimited (in place and time) tool (that is also valuable in information collection tool) for Citizens' Engagement into Responsible Research and Innovation (RRI) processes. Here, we deal with creating mutual understanding, responsible, transparent and knowledge-based action between all societal actors for support of long-term sustainable growth of nations and regions, e.g., Europe. Additionally, we present examples of its use in daily life by one of the most proactive $\mathrm{CSO}$ in EU.

\section{Responsible Research and Innovation}

R\&I are flagship initiatives of the EU2020 development strategy, which should support long-term sustainable growth of Europe and support EU's economy to become more competitive compared with other world regions, such as the USA, Japan and S. Korea, China and Russia. Nowadays, the EU is (probably) ahead in key science and technology area (health, food, renewable energies and environmental technologies) due to positive changes in Europe's ecosystem for innovation. However, the economic effect of R\&I investments depends on the knowledge-oriented and innovation-driven economies of Member States ${ }^{4,5}$ and there is still work in these matters.

Knowledge-based innovation-driven economy depends on cross-cutting issues and trans-disciplinary solutions which foresee liaison of different groups of stakeholders. According to this, R\&I systems need to be transformed into Responsible and Collaborative R\&I systems. "Responsible Research and Innovation means that societal actors work together during the whole research and innovation process in order to better align both the process and its outcomes, with the values, needs and expectations of European society". ${ }^{1}$

Even if the terms "responsible innovation" and "Responsible Research and Innovation" have a long history, just in the last four years, these are starting to have effects, mostly within the Science in Society programme (Horizon 2020 programme). RRI becomes the approach and instrument to respond effectively and urgently to the grand societal challenges: climate change, ageing population, food, water, materials and energy safety, public health, and security ${ }^{1,5,6}$ migration as well.

The framework of the RRI proposed by EU consists of six main elements: Gender Equality, Science Education, Ethics, Open Access, Governance and the leading one - Engagement and cooperation of all societal actors. The researchers, industries, policymakers and civil society in joint R\&I participation should focus on a specific global challenge for global sustainability. This is a societal demand-driven 
strategy. Here, special attention is given to citizens, as their participation is not only at the center of attention of local government but also a growing field of academic research for researchers, which can explore international engagement practices and adapt them to local community needs. ${ }^{1,2,6}$ However, different obstacles limit such cooperation: understanding of needs, different visions, communication practices, institutional barriers, knowledge-sharing practices, financial limits, etc. During the last decades, the CSOs have played a key role in pushing for sustainable development at the local, regional, national and international levels. They became a connecting element for cooperation between different groups of stakeholders. Supported by advances provided by ICT tools and social media, CSOs help one to focus attention on the social, political and environmental components of the social and business activities.

Different economic, political and behavioral factors (changes in F2F to online communication, mutual trust and understanding of value) are hidden in RRI concept. Mobility of people, changing economic conditions, democratic processes, changes in demographic situation, etc., stimulate unstable conditions of Social Actors Cooperation in the RRI processes. Meanwhile, according to a Euro-barometer inquiry performed in 2013, regarding the European citizens' attitude to the science and innovation, respondents declared that science and technology make a positive influence on the society ( $77 \%$ of respondents), underlying that the R\&I activities must take place with proper attention to ethics $(76 \%$ of the respondents). This supports the hypothesis that citizens would be interested in participation in RRI activities and are ready for collaborative relationships with research community, business, policymakers and local authorities. So the key question is how this cooperation and participatory approach can be motivated, organized and recognized?

\section{Social Media for Social Actors Cooperation}

The social media has received increased interest and attention in recent years due to its growing popularity by different societal actors and wide use. Social media provides:

- Strategy for representation of ideas and exchanges of needs and knowledge.

- It is an engagement tool, low cost and fast in the frames of the individual reaction.

- It provides opportunities to create personal and professional networks. ${ }^{3}$

It can also be described as an ensemble artefact whose components are technology, information and social structure. The initial component relates to the capacity to engage in social and professional circles (social artefact) through social media technologies (technology artefact) to create opportunities for communicating and managing information (information artefact). ${ }^{7}$

Additionally, it is important to underline that social and online media provokes social actors by its content, creating a field for debates and understanding of values, 
which are more than just important for RRI and directly correlate with ethical questions. This communication and information exchange tool creates opportunities to avoid barriers mentioned before and to be informed about ongoing and future local, regional and EU development, creating the concept of the so-called "online societies". "Online societies" are societies, which are not linked by territorial and physical places, they work online, $24 \mathrm{~h}$ per day and react fast to instant news, and creating a personal opinion about this news and margining in groups, they represent their thoughts and needs. Such behavior influenced characteristics of the XXI century; it is a century of social media. There is a significant value of the social and online media as it became a support tool for e-governance, health sector, crisis management, academic performance and of course daily communication between different target groups. It provides a practical tool for democratic engagement practices and exchanges between local problem-solving initiatives and rather globally-oriented professional knowledge and expertize in RRI.

Thus, allowing everyone to participate in digital activism on various issues, the social media is taking a role in defining areas for engagement and mobilizing individuals for civic action. To some extent, civic engagement refers to the individual or collective involvement of citizens in addressing social issues. ${ }^{8}$ Social media helps create a collaborative relationship with the stakeholders. Moreover, it provides access to real-time data created by their stakeholders, seeks information about stakeholders and receives feedback about provided services and it is a cost-efficient way of communication. ${ }^{9}$

The initial idea of the social media was to create social and professional circles (social artefact) using social media technologies (technology artefact) stimulating, communicating and managing information (information artefact). With this natural development, the social media became a communication system and digital platform that facilitates individual and social participation with publicly available data. New social practices are being developed, and nowadays, social media represent a "virtual" community with community-sustained roles in which users are provided with an environment allowing for an easier interaction with other stakeholders. ${ }^{7}$ Such interaction reinforces the sense of community and helps in building up citizenship in a participatory process.

The social media stimulates Citizen Engagement from a learning perspective as it provides new information for development of citizens' knowledge and understanding of the operation of the political and administrative system and their civic rights to influence it. This is a type of non-formal learning, which stimulates cooperative learning and analytical skills of the user. ${ }^{2,10}$ Meanwhile, citizen participation is mostly about providing and gaining information, assistance and support from citizens, it does not necessarily mean true engagement, which is about reinforcing the sense of community and building up citizenship. Citizen engagement, the most preferred approach these days, is interaction, a reciprocal form of exchange instead of the traditional one-way "exchange" of information between the government and citizens. ${ }^{2}$ Such communication would be a golden basis for Social Actors' 
Cooperation into RRI. But social actors engagement requires information sharing and interaction among different stakeholders based on several principles: transparency — sharing knowledge and information among multiple stakeholders; interaction - dialogue among multiple stakeholders about the purposes of innovation processes and the risks involved; responsiveness and co-responsibility — interaction with stakeholders in order to become mutually responsive to each other. However, these processes are overloaded by critical issues regarding social actors engagement into RRI and collaborative RRI (see Table 1$).{ }^{11}$

According to Chun and Luna-Reyes, ${ }^{12}$ there are three schematic representations of how government, citizens, and data models interact through social media (social media-based citizen engagement model; social media-based data sharing model; and social media-based real-time collaborative government model). ${ }^{12} \mathrm{Such}$ data help CSOs to indicate a target group and to involve citizens into discussions, contributing to the governance policies. The social media in governance stimulates co-production of public (shares responsibility) policies, collection of solutions to social and political problems, and political and democratic engagement in a growing dialogue about political, economic, demographic and other issues. ${ }^{13}$ Best practices of social media use should be analyzed and transferred to RRI in order to foster higher citizens' engagement in research processes. One of the most representative examples of use of social media in society is social media in the e-government websites. It supports administrative reforms, democratic, and participatory citizen engagement with two core principles: collaboration and engagement. ${ }^{14,15}$ Thus, it is important to understand the social, technological, related matters that influence those principals.

Table 1. Theoretical framework: critical issues with regard to stakeholder engagement in responsible innovation and management practices for dealing with these concerns. ${ }^{11}$

\begin{tabular}{ll}
\hline $\begin{array}{c}\text { characteristics of } \\
\text { SEiRI }\end{array}$ & Critical issues with regards to stake- \\
holder engagement \\
Transparency & Decrease of competitive advantage \\
& Lack of control \\
& Fear of knowledge leakage
\end{tabular}

Interaction

Different visions, goats, motives, sectors, and values Power imbalances

Responsiveness

Co-responsibility
Different visions, goats, motives, sectors, and values

Investment decision responsibility of the investor alone Co-responsibility may result In legitimacy losses or NGOs
Management practices for dealing with these concerns

Intellectual property management

Semi-formal protection methods

First mover advantage

Design complexity

Building trust

Dialogue and relationship building Commitment

Formal socialization mechanisms

Informal socialization mechanisms

Aligning partners' expectations, experience, and identity Acceptance of conflict 
All these benefits should be proceeded for RRI in correlation with the understanding who is a user of social media tool, who is the manager and what are their interests. XXI century is described as a century of Z-generation. This generation is a generation, which can be characterized as a digital one, which accepts faster short messages, have good digital skills, with an active participation in social life. For them, social networking sites have become a daily communication tool. ${ }^{16-18}$ Nevertheless, there are cross-cultural differences in the field of digital skills in EU countries, and digital skills are the most important for online communication. For example, there is big gap between elder and young generations in the use of digital tools in daily life in postsoviet countries while, Nordic countries do not face such differences. As a consequence, most research conducted with regard to online communication concentrated on young generations, while for RRI, the core accent should be given to more experienced people, and with them, situation is different in different countries around Europe region. This is why the role of CSOs is crucial, CSOs not only represent social groups, with their activities, but also stimulate learning processes of individual, contributing to the lifelong learning process.

According to Brossard, ${ }^{19}$ citizens are increasingly motivated to look for information about science and to follow scientific developments online as scientists gained powerful tool for information sharing - social media. Nowadays, the reality is that scientists, research organizations support direct communication with unspecialized audiences, discuss scientific findings online, so share and produce science content, by making and posting videos, blog posts, or just by commenting them online. The online environments increase public knowledge levels about a wide range of topics by providing easier access to information. On the other side, citizens are happy to share their opinions about science topics as they feel science impact on their communities (for example, energy questions, climate changes, etc.). ${ }^{19}$ In a hidden way, such participation stimulates cooperative learning, develops analytical skills of citizens, and contributes to the knowledge creation on local and regional levels. Moreover, scientists are able to accept evidence-based decision and plan actions, which directly involve citizens as local experts.

To summarize, social media can play a core role in governmental and research processes, and all of us should understand the value. It provides important and valuable information about citizens (i.e., age, gender, education level, income, and employment status, among others) and the way that citizens can affect research policies. Such elements define the position of an individual in the framework of his social and economic relationships. This can be used for the search of target group and the identification of interests, transferring them to user-generated content and thus stimulating the public debate about the proposed topic in RRI involving policy makers visibly on discussions about the future and shape of EU policies and institutions. ${ }^{21-23}$ Using social media in this way, CSOs can be closer to the real needs of the society and create development strategies for a better tomorrow. As a result, the social and online media are actively used by CSOs for information and 
communication with citizens on local and national levels. The main hypotheses for these communications are as follows:

- Through the information dissemination process, the social media creates a strong impact on citizen's behavior considering EU development policies.

- Social media is a transparency and trust tool for public dialogue and discussions regarding well-being creation aspects in EU.

\section{Examples of CSO Activities with Society}

CESIE is one of the most proactive CSOs in EU, it is European Centre of Studies and Initiatives established in Palermo with more than 15 years' experience in educational, social, economic, and cultural projects. The organization plays a key role in regional development by ensuring the necessary connection between studies and initiatives with a variety of target groups involved (public authorities, communities, adults, youth, entrepreneurs, migrants, women, etc.). As the most interactive tool for communication with stakeholders and creation of action-based results, it uses social and online media, and some examples of CESIE's initiatives are presented below:

— "Step by Step" is a Horizon 2020 project aiming at reducing energy consumption of households and encouraging them to invest in energy-efficient products and/or high quality renewable energy. Communication strategies involving direct contact and mass media campaigns are used effectively in this project. Thus, Step by Step aims at provoking behavioral change in participating households by regularly encouraging them to try and commit to new actions to reduce energy consumption. After the first phase of individual door-to-door contact with households, the targeted households are regularly solicited through email or by phone and will be accompanied over a 20 month period towards the adoption of energy-saving practices. Different social media tools, inviting participants to use an interactive online platform, support the communication process. It allows them to check their progress and engage in new energy-saving actions regularly. The methodology adopted in "Step by Step" allows motivation of households to adopt sustainable consumption patterns and to contribute to the development of new behavioral standards.

_ "YouthMetre" and "We all count Europe" are projects of the Erasmus + Programme, Key Action 3 - Support for policy reform. Project partners have been working to develop innovative e-tools and activities to engage young people and help them influence youth policy, creating contacts with public authorities and policymakers, to make them aware of the concerns of young people and help them to use young people's suggestions to shape the youth policy in EU. To stimulate the use of the e-portals of the projects and involvement of societal actors into activities of the projects, Facebook, Twitter, Instagram, and other social media 
tools are used by partners. The e-portals of the projects are the main e-tools that will be used to increase democratic participation of young people.

The Moldavian DAS Foundation, launched in 2013, is a not-for-profit socioeconomic organization. The goal here is to advance science and innovation in Moldova, to spread ICT knowledge and to bring anyone interested in these domains on board, citing Moldova is great potential to grow through education, science, innovation, and ICT projects. Today, DAS Foundation is the co-organizer of two events that advance science and innovation in Moldova. Both Science SLAM Moldova and the European Researchers Night have been created in collaboration with the Academy of Sciences of Moldova, the Center for International Projects, and H2020 National Contact Points Network. Also, beyond these events, DAS organizes activities to advance science and technology in the communities, e.g., create a codingschool project, and develop the current projects on scale in every Moldovan city. DAS is working to advance the collaboration beyond Moldova with any organization that has similar interests, missions, and goals, including scientific groups around the world.

\section{Conclusions}

The EU is working to create a sustainable and creative region, and for this, the impact on society development should be achived through cooperation between societal actors, and the power structure should be created. As cooperation is a learning process, the leading role for the creation of links between stakeholders and citizens should be led by the CSOs due to their basic properties, history and reached results.

It is visible that the use of social media offers CSOs tools to work more productively, stimulate discussions, consistently to stay in contact with the target groups, contribute to the significant changes in socio-economic and political areas. In parallel, it expands awareness and motivates citizens to participate in the decisionmaking process personally and share the responsibility for the outcomes. As a result, the entire society benefits from such close cooperation between different groups of stakeholders, creating best examples of interaction practices, development of policies connected to real needs, society-oriented R\&I actions, development of well-being for the future.

Among the examples where socio-economic organizations form the management of activities that can influence daily life (beyond those that were presented about e-policies and energy consumption balances) are development of crowd funding to compete with biased banks, development of legal suggestions from social activities through unique websites (that are developed for these activities) to press on the political system with these laws, and creation of alternative unbiased media. All these can shift control (on opportunities, wealth, etc.) to the direction of the citizens from the policy makers and the elite that tend to concentrate on the control in that circle. 


\section{Acknowledgments}

We are thankful to Dr. Iulia Iatco for the information about the Moldovian DAS foundation.

\section{References}

1. European Union, Responsible Research and Innovation. Europe's Ability to Respond to Societal Challenges (European Commission, Belgium, 2012), p. 4.

2. Á. Dobos and Á. Jenei, Citizen engagement as a learning experience, 3rd World Conf. Learning, Teaching and Educational Leadership (WCLTA-2012), Proc. Soc. Behav. Sci. 93 (2013), pp. 1085-1089.

3. K. Mossberger, Y. Wu and J. Crawford, Connecting citizens and local governments? Social media and interactivity in major U.S. cities, Gov. Inf. Q. 30 (2013), pp. 351-358.

4. European Union, Research and Innovation performance Innovation Union progress at country level in the EU. Innovation Union progress at country level (2014), p. 364.

5. R. Owen, P. Macnaghten and J. Stilgoe, Responsible research and innovation: From science in society to science for society, with society, Sci. Publ. Policy 39 (2012) 751-760.

6. M. Deblonde, Responsible research and innovation: Building knowledge arena $\mathrm{s}$ for glocal sustainability research, J. Responsib. Innov. 2(1) (2015) 20-38, doi: 10.1080/ 23299460.2014.1001235.

7. P. Spagnoletti, A. Resca and Ø. Sæbø, Design for social media engagement: Insights from elderly care assistance, J. Strateg. Inf. Syst. 24 (2015) 128-145.

8. A. M. Warren, A. Sulaiman and N. I. Jaafar, Social media effects on fostering online civic engagement and building citizen trust and trust in institutions, Gov. Inf. Q. 31(2) (2014) 291-301.

9. M. Roshan, M. Warren and R. Carr, Understanding the use of social media by organisations for crisis communication, Comput. Human Behav. 63 (2016) 350-361.

10. A. Petrescu, G. Gorghiu and R. A. Lupu, Non-formal education - frame for responsible research and innovation demarches. The 6th Int. Conf. Edu World 2014 "Education Facing Contemporary World Issues", Procedia-Soc. Behav. Sci. 180 (2015) 682-687.

11. V. B. Related, L. Hoffmans and E. F. M. Wubben, Stakeholder engagement for responsible innovation in the private sector: Critical issues and management practices, J. Chain Netw. Sci. 2 (2015) 147-164, doi: http://dx.doi.org/10.3920/JCNS2015.x003.

12. S. A. Chun and L. Luna-Reyes, Social media in government, Gov. Inf. Q. 29 (2012) 441-445.

13. J. I. Criado, R. Sandoval-Almazan and J. Ramon Gil-Garcia, Government innovation through social media, Gov. Inf. Q. 30 (2013) 319-326.

14. E. Bonsón, S. Royo and M. Ratkai, Citizens' engagement on local governments' Facebook sites. An empirical analysis: The impact of different media and content types in Western Europe, Gov. Inf. Q. 32(1) (2014) 1-11.

15. D. Agostino, Using social media to engage citizens: A study of Italian municipalities, Public Relat. Rev. 39 (2013) 232-234.

16. E. H. Jung and S. S. Sundar, Senior citizens on Facebook: How do they interact and why? Comput. Human Behav. 61 (2016) 27-35.

17. M. Ozkana and B. Solmaz, The changing face of the employees - generation $\mathrm{Z}$ and their perceptions of work (a study applied to university students), Procedia Econ. Financ. 26 (2015) 476-483.

18. K. Gargi and M. Maitri, Gen Z - Children of digital revolution transforming social landscape, Am. Int. J. Res. Humanit. Arts Soc. Sci. 10(3) (2015) 206-208. 
19. D. Brossard, New media landscapes and the science information consumer, Proc. Natl. Acad. Sci. USA 110 (2013) 14096-14101.

20. Y. K. Sara, Public engagement with and communication of science in a web -2.0 media environment, American Association for the Advancement of Science, white paper, December 2015, p. 22. Available online: http://www.aaas.org/sites/default/files/content_files/public\%20engagement\%20social\%20media_Yeo_single.pdf.

21. J. Benthaus, M. Risius and R. Beck, Social media management strategies for organizational impression management and their effect on public perception, J. Strat. Inf. Syst. 25(2) (2016) 127-139.

22. P. Nulty, Y. Theocharis, S. A. Popa, O. Parnet and K. Benoit, Social media and political communication in the 2014 elections to the European Parliament, Elect. Stud. 44 (2015) 429-444.

23. M. Vicente and A. A. Novo, An empirical analysis of e-participation. The role of social networks and e-government over citizens' online engagement, Gov. Inf. Q. 31 (2014) 379-387. 